\title{
Approach and escape to conspecific odors of reward and nonreward in rats*
}

\author{
ROGER L. MELLGREN, ROGER S. FOUTS, and JOHNSON W. MARTIN \\ University of Oklahoma, Norman, Oklahoma 73069
}

\begin{abstract}
A three-compartment box was used, and a reward odor, or nonreward (extinction) odor, produced by another rat, was present in the middle compartment. Two control odor procedures were also used. The results showed that rats will approach a location in which another rat has previously been given reward more rapidly than they will escape from that location, but showed the opposite effect when the odor was produced by a rat undergoing extinction. The mere presence of an odor associated with another rat had the effect of producing much slower locomotion as compared to a no-odor control condition.
\end{abstract}

Olfactory stimuli produced by other rats have been shown to be important determinants of the speed of running to a simple alternating schedule of reward and nonreward (Amsel, Hug, \& Surridge, 1969) and also to a double alternating schedule of reward and nonreward (Ludvigson \& Systma, 1967). It has also been shown that a nonreward odor produced by a donor rat at the choice point of a T-maze may serve as a discriminative stimulus for a left or right turn in the maze, but a reward odor does not seem to function in the same manner (Morrison \& Ludvigson, 1970). These results may be interpreted as indicating that rats leave different odor trails depending on reward conditions and that these odor trails may serve as discriminative stimuli.

In addition to having a cue function, it has been suggested that there may be unconditioned responses associated with different odor trails (Collerain \& Ludvigson, 1972; Sprott, 1969). The hypothesis used in designing the present experiment was that the odor trail associated with nonreward would act as an unconditioned aversive stimulus, while the odor trail associated with reward would act as an unconditioned attractive stimulus. There is some ambiguity in the existing data on the unconditioned effects of odor trails. One experiment showed that a nonreward trail produced by rats undergoing extinction could disrupt rewarded runway performance of other rats (Wasserman \& Jensen, 1969). Although this finding is consistent with the hypothesis offered above, it is far from conclusive, since the nonreward odor trail may have disrupted performance only because of a change in stimulus conditions-i.e., stimulus generalization decrement. It was also demonstrated that continuously rewarded rats running in the presence of reward odor trails did not

\footnotetext{
*The authors wish to thank Dan M. Wrather for his assistance. Partial support of this research was provided by an institutional grant to the University of Oklahoma from the National Science Foundation. Requests for reprints should be sent to Roger $L$. Mellgren, Department of Psychology, University of Oklahoma, Norman, Oklahoma 73069.
}

differ from control (no odor) rats in start speeds, but were somewhat inferior in the run speed measure. Although this finding appears contradictory to our hypothesis, it should be noted that the slowest rats were selected to produce the reward odor trail, perhaps biasing the results against showing a facilitative effect since the slowest rats may have been more fearful of the experimental apparatus. Collerain and Ludvigson (1972) have shown that experimental Ss will tend to avoid one arm of a T-maze where a donor rat has received nonreward, but do not show a preference for entering an arm where a donor rat has received reward. In these experiments, the odors were produced by rats experiencing a partial reinforcement schedule, and the donor rats could have produced confounded odors due to the anticipation of reward or nonreward. Data that are consistent with our hypothesis include an experiment showing that rats run faster in the presence of $\mathrm{S}+$ odor trails than of $\mathrm{S}$ - odor trails produced by $\mathrm{Ss}$ that had undergone differential conditioning (McHose \& Ludvigson, 1966). These data do not allow evaluation of the influence of the S+ and S- odor trails relative to a neutral (control) condition.

To test the hypothesis that rats emit different odors depending on the occurrence or nonoccurrence of reward, a three-compartment box was used. The middle compartment of the box contained paper which had been present when a donor rat (a) had been rewarded, (b) had been nonrewarded after a previous period of reward (extinction, or "frustration"), or (c) had never received any reward in the situation (control). The two end compartments always had clean paper on the floors. Finally, a baseline condition was used where there was no odor of a conspecific present in the apparatus (i.e., clean paper throughout).

If rats emit a distinctive odor when undergoing extinction, and if this odor is an aversive stimulus to other rats, then it would be expected that the experimental Ss (Group N) would be reluctant to enter the middle compartment where the extinction odor was located and would leave relatively rapidly once there. 
Table 1

Mean Approach and Escape Times in Seconds and Mean Difference Scores (Escape Minus Approach Times) Across All Days

\begin{tabular}{|c|c|c|c|}
\hline \multirow[b]{2}{*}{ Group } & \multicolumn{2}{|c|}{ Time Measure } & \multirow{2}{*}{$\begin{array}{l}\text { Diffe- } \\
\text { rence } \\
\text { Scores }\end{array}$} \\
\hline & Approach & Escape & \\
\hline $\mathrm{R}$ & 26.49 & 60.49 & 34.00 \\
\hline $\mathrm{N}$ & 56.27 & 32.62 & -23.65 \\
\hline C & 44.83 & 54.65 & 9.82 \\
\hline NO & 11.74 & 7.46 & -4.28 \\
\hline
\end{tabular}

Conversely, if the odor in the middle compartment was produced by a rewarded rat, and if this odor is an attractive stimulus to other rats, it would be expected that the experimental Ss (Group R) would enter the middle compartment relatively quickly and be reluctant to leave once there. These predictions are all made relative to the control procedure where the general odor of another rat (produced by allowing the donor rat to simply explore the apparatus) was present in the middle compartment (Group C).

It is possible that any type of conspecific odor might have an effect on the rat. Specifically, the rats in Group C experienced a "general odor of another rat." It is not unlikely that this general odor might have either attractive or aversive properties. In order to assess these possibilities, a second control group (Group NO) experienced clean paper in all three compartments. Differences between Groups $\mathrm{C}$ and NO allow assessment of the degree of attractiveness or aversiveness of the odor produced by a rat that is simply allowed to explore the apparatus.

\section{METHOD}

\section{Subjects}

A total of 54 male albino rats, 110 days old, of the Sprague-Dawley strain were put on a $23 \frac{1}{2}-\mathrm{h}$ water-deprivation schedule with food available ad lib.

\section{Apparatus}

The three-compartment box measured $114.9 \times 13.4 \mathrm{~cm}$ and was $15.2 \mathrm{~cm}$ in height. The top of the apparatus consisted of wire mesh, and the two guillotine doors divided the apparatus into three equal-sized chambers. The floors of each chamber consisted of white butcher paper which could be changed by pulling it through slots in the bottom of the side walls of the apparatus. The first section of the apparatus was designated as the startbox (SB), the second section was designated as Goalbox 1 (GB 1), and the last section as Goalbox 2 (GB 2).

\section{Procedure}

Two donor groups received 24 continuously rewarded trials (.5 cc of water in both GB 1 and GB 2), and the third donor group received the same number of trials with no rewaid in the apparatus $(\mathrm{N}=9 /$ group). For the next 15 trials, one rewarded group of donors continued to receive continuous reward in GB 1 and GB 2 and the second rewarded group was changed to nonreward in $G B 1$ and GB2. The third group continued to receive nonreward in both $\mathrm{GB} 1$ and $\mathrm{GB} 2$. Each $S$ had three trials per day with clean paper in all compartments. An intertrial interval of at least 2 min was used.

For the last 12 trials ( 4 days). the experimental groups $(\mathrm{N}=$ $9 /$ group) were run following the appropriate donor. None of the experimental Ss were given any prior experience or any primary reward (i.e., water) in the apparatus. Group $R$ was run following the donors that received water in GB 1 and GB 2. Group $N$ was run following the donors that experienced extinction in GB 1 and GB 2 [the donor Ss had 1 day (3 trials) of extinction preceding the first day of testing for Group N]. Group C was run following the continuously nonrewarded (exploratory) donors. Group NO consisted of the same Ss as the exploratory donors, since clean paper was present in all chambers, and their data were taken from the first 4 days. In summary, there were six groups of nine rats. Three donor groups received 39 trials (3/day). On the last 12 trials, three experimental groups ( R, N, and $C$ ) were run following a donor that received continuous reward, nonreward (extinction), or continued exploration. The exploration donor group was also used as a second control group (NO) which received clean paper throughout.

After each donor trial, the paper in the SB and GB 2 was replaced with fresh paper, so that only $G B 1$ had the donor odor present. Time for the $S$ s to leave the $S B$ and enter $10.2 \mathrm{~cm}$ into GB 1 (approach) and time to leave GB 1 and enter either $10.2 \mathrm{~cm}$ into $G B 2$ or $10.2 \mathrm{~cm}$ into the $S B$ (escape) were measured to the nearest 100 th of a second.

A trial for all $S$ s was exactiy the same. The $S$ was placed in the $S B$, and 5 sec later the SB door was opened. After the $S$ moved into GB 1, the SB door was lowered. After $10 \mathrm{sec}$ had elapsed, the door separating GB 1 and GB 2 and the SB door were raised. After leaving GB 1, the appropriate door was lowered to prevent return to $G B 1$ and the $S$ was removed in $10 \mathrm{sec}$.

\section{RESULTS}

An analysis of variance of the four groups across the 4 testing days was performed on approach times, escape times, and also on difference scores (escape minus approach times). Since the days factor and the interaction of Days by Groups were not significant in any of the analyses, the mean times across days are presented in Table 1. The first result which is most striking in Table 1 is the large differences in approach and escape times in the NO group as compared to the other groups. When no odor of any sort was present in the middle compartment, the Ss ran through the apparatus much more quickly than when there was an odor present in the middle compartment (regardless of the kind of odor). Thus, it is not surprising that if only an approach response is used in a runway, a reward odor may have disruptive effects (e.g., Wasserman \& Jensen, 1969). When the difference score measure is used, it is clear that the NO group is closest to zero, but a comparison of Groups NO and $\mathrm{C}$ revealed that they were significantly different $(p<.01)$ from each other. The interpretation of this difference appears to be that the odor of another "neutral" rat is slightly positive, since the Ss in Group C tended to approach quicker than they left the area associated with the odor.

The second finding, which is fairly clear in Table 1 , is that the reward odor serves as an attractive stimulus, while the nonreward odor serves as an aversive stimulus. The analysis of approach times resulted in a significant 
main effect for groups $(F=32.18, \mathrm{df}=3 / 32, \mathrm{p}<.001)$. Comparisons based on a post hoc correction procedure (Scheffé) revealed that all groups were significantly different from each other at the .05 level of significance or better. In other words, Group $\mathrm{R}$ approached the odor compartment more rapidly than did Group $\mathrm{C}$ and Group $\mathrm{C}$ approached more rapidly than did Group $\mathrm{N}$, as would be predicted if reward and nonreward result in odors which are attractive and aversive, respectively. The analysis of escape times also resulted in a highly significant main effect of groups $(F=37.00, d f=3 / 32$, $\mathrm{p}<.001$ ). Again, all groups differed from each other at the .05 level of significance or better except for Groups $\mathrm{R}$ and $\mathrm{C}$, consistent with the already mentioned hypothesis that the odor of another "neutral" rat is mildly attractive. Finally, the analysis of difference scores also revealed a significant groups effect $(F=$ 23.35 , df $=3 / 32, p<.001$ ), with all groups being significantly different from each other at better than the .05 level.

\section{DISCUSSION}

On the basis of the present data, a major question which must be answered involves the interpretation of the absolute time (approach and escape) and the difference score measure. Consider Groups $\mathbf{R}$ and $\mathbf{N}$. The approach times for Group $R$ were significantly greater than for Group NO (which is consistent with Wasserman \& Jensen, 1969). On the basis of this finding, it could be argued that the odor produced by a rewarded rat (reward odor) is actually aversive, since Group R was slower to approach that odor than was the control group (NO) that had no odor (other than the paper) present. On the other hand, Group R was significantly slower in leaving the reward odor than was Group NO in leaving the "clean" odor. From this finding, it could be argued that the reward odor is an attractive stimulus which holds the rat in the middle compartment. This would account for the fact that Group $\mathrm{R}$ took about eight times as long to leave the middle compartment as did Group NO. This same paradoxical interpretation can also be made for Groups $\mathrm{N}$ and $\mathrm{C}$ in comparison to Group NO.

The difference score measure allows a much clearer interpretation of the data. The difference scores were obtained by subtracting approach times from escape times, and therefore positive scores should indicate the presence of an attractive stimulus and negative scores should indicate the presence of an aversive stimulus. Unfortunately, this statement is true only if we accept the assumption that the physical zero point (i.e., escape minus approach equals zero) is also the behavioral zero point. There would seem to be no good reason for accepting the equivalence of these two zero points other than intuition. Given this problem, there are two possible choices for a behavioral zero point (Groups $\mathrm{C}$ and NO). Since these two groups were significantly different from each other on the difference score measure, it might appear that any interpretation is impossible. There are two ways around this problem. First, it might be argued a priori that one of the groups is "more appropriate" than the other as a control. For example, Group $\mathrm{C}$ might be deemed more appropriate than Group NO since Group $C$ encountered an odor in the middle compartment (like Groups $\mathbf{N}$ and $\mathrm{R}$ ) but Group NO did not. Unfortunately, it is possible to argue that the donor Ss for Group C may have left some odors which were attractive or aversive as a function of the handling they received. Of course, it could also be argued that the donor Ss for Groups $\mathrm{N}$ and $\mathrm{R}$ also received the same amount of handling, so this factor would be constant across Groups $\mathrm{N}, \mathrm{R}$, and $\mathrm{C}$. These considerations seem to provide more of a basis for deeming Group $C$ the appropriate- control group, but since it was clear that such a conclusion was not possible without some degree of ambiguity, Group NO was included. This leads to a second way of dealing with the zero-point problem. Simply choose that either control procedure and conclusions concerning Groups $\mathbf{N}$ and $\mathrm{R}$ are the same (with respect to difference scores). Group $\mathrm{N}$ was significantly inferior to both Groups $\mathrm{C}$ and NO, and Group $R$ was significantly superior to both Groups $C$ and NO. This supports a conclusion that rats emit odors associated with reward and nonreward, and these odors serve as attractive and aversive stimuli, respectively. If Group $C$ is used as the control group, then approach and escape times allow for almost the same conclusion. Approach times indicate both the attractive and aversive properties of the reward and nonreward odors. Escape times do not lead to such an unambiguous interpretation. The difference between Groups $\mathrm{C}$ and $\mathrm{N}$ indicates that the nonreward odor is an aversive stimulus, but the lack of difference between Groups $C$ and $R$ does not support the interpretation that the reward odor was an attractive stimulus.

It would seem safe to conclude that the odor produced by a rat when it receives nonreward is an aversive stimulus and the odor produced by a rat when it receives reward may be an attractive stimulus. Furthermore, these odors do not appear to be transmitted via feces or urine, since it was rare when such excretions were present. If they were present, they were removed and blotted before the experimental $S$ was placed in the apparatus. It is tempting to postulate that the response of rats to these odors is not learned, but a note of caution should be made since special rearing conditions controlling experiences with the odors are needed to make this conclusion in an unambiguous manner.

It should be noted that the present experiment was based on an earlier unpublished study. In this earlier study, the donor Ss were given partial reinforcement: following nonrewarded trials the odor was used for an $\mathrm{N}$ group, and following rewarded trials the odor was used for an $\mathrm{R}$ group. This procedure produced many fewer 
striking differences than did the procedure used in the present experiment, possibly due to a "mixed odor" being produced by the donor rat because of previous reward and nonreward experiences both within each day and between days. These mixed odors could have been due to the anticipation of reward $\left(\mathrm{r}_{\mathrm{g}}\right)$ and/or frustration $\left(\mathrm{r}_{\mathrm{f}}\right)$ in the donor rats on nonreward and reward trials, respectively. This could also explain why Morrison and Ludvigson (1970) failed to find a long-lasting effect due to only reward odors in maintaining a discrimination. It is interesting, however, that there was an apparent effect of reward odors during the early part of training (i.e., Trials 13-20) in the Morrison and Ludvigson experiment, raising the possibility that the attractiveness of an odor associated with reward in the present experiment might decrease, or somehow change, with continued testing. Similarly, the nonsymetric findings of Collerain and Ludvigson (1972) (i.e., "frustration odor" was avoided but "reward odor" was not approached) may be confounded by the fact that the donor odors were produced by rats experiencing a partial reinforcement schedule.

\section{REFERENCES}

Amsel, A.. Hug, J. J., \& Surridge. C. T. Subject-to-subject trial sequence, odor trails, and patterning at 24-h ITI. Psychonomic Science, 1969, 15, 119-120.

Collerain. I.. \& Ludvigson. H. W. Aversion of conspecific odor of frustrative nonreward in rats. Psychonomic Science. 1972, 27. 54-56.

Ludvigson, H. W.. \& Systma, D. The sweet smell of success: Apparent double alternation in the rat. Psychonomic Science. 1967, 9, 283-284.

McHose, J. J.. \& Ludvigson, H. W. Differential conditioning with nondifferential reinforcement. Psychonomic Science. 1966, 6, 485.

Morrison, R. R., \& Ludvigson. H. W. Discrimination by rats of conspecific odors of reward and nonreward. Science, 1970, 167, 904-905.

Sprott, R. C. "Fear communication" via odor in inbred mice. Psychological Reports, 1969, 25. 263-268.

Wasserman, E. A., \& Jensen, D. D. Olfactory stimuli and the "pseudo-extinction" effect. Science, 1969, 166, 1307-1309.

(Received for publication October 30, 1972; revision received January $18,1973$. 